\title{
Secondary amenorrhea in a case of gonadotropin independent precocious puberty: McCune-Albright syndrome
}

\author{
Sridhar Subbiah ${ }^{1}$, Roshan Nazirudeen ${ }^{1}$, Sundari Natarajan ${ }^{2}$, \\ Vasanthiy Natarajan', Sangumani Jayaraman ${ }^{1}$
}

\begin{abstract}
${ }^{1}$ Department of Endocrinology, ${ }^{2}$ Department of Radiology, Government Rajaji Hospital and Madurai Medical College, Madurai, Tamil Nadu, India
\end{abstract}

Received: 21 July 2021

Revised: 16 August 2021

Accepted: 17 August 2021

\section{*Correspondence:}

Dr. Roshan Nazirudeen,

E-mail: roshans1989@yahoo.com

Copyright: (C) the author(s), publisher and licensee Medip Academy. This is an open-access article distributed under the terms of the Creative Commons Attribution Non-Commercial License, which permits unrestricted non-commercial use, distribution, and reproduction in any medium, provided the original work is properly cited.

\begin{abstract}
Precocious puberty may be gonadotropin dependent or gonadotropin independent and due to a myriad of causes including syndromic association. McCune-Albright syndrome (MAS) is a rare disorder, characterized by the triad of precocious puberty, polyostotic fibrous dysplasia of bone and café-au-lait macules. Here, we describe a case of childhood onset gonadotropin independent precocious puberty who presented at 19 years of age with secondary amenorrhea. On detailed evaluation, she was found to have multiple café au lait spots and polyostotic fibrous dysplasia and diagnosis of MAS were made. Typically, the lesions of fibrous dysplasia are most active during childhood and adolescence, tending to become quiescent in adult life, new active lesions being rare in adults. In our case, despite fibrous dysplasia being asymptomatic on presentation, there were multiple active polyostotic lesions with bilateral encroachment of optic foramina, which is rare at this age. This case highlights the fact that careful examination for syndromic features and periodic follow up are important in all cases of precocious puberty.
\end{abstract}

Keywords: McCune-Albright syndrome, Precocious puberty, Amenorrhea, fibrous dysplasia, Café au lait macules

\section{INTRODUCTION}

Precocious puberty is the appearance of secondary sexual characteristics before the normal limit of age of onset of puberty for the race and sex of the individual. It may be gonadotropin dependent or gonadotropin independent. McCune-Albright syndrome (MAS) is a rare condition associated with typically gonadotropin independent precocious puberty, having an estimated prevalence of $1 / 100,000$ to $1 / 1,000,000 .^{1,2}$ Here we report a case of precocious puberty, presenting at the age of 19 years as secondary amenorrhea, found to have café au lait macules and polyostotic fibrous dysplasia on evaluation, diagnosed as MAS. The objective of this case report is to sensitize primary health care providers, pediatricians and gynecologists of the possibility of this syndrome in cases of precocious puberty and emphasize the importance of meticulous clinical examination and close follow up.

\section{CASE REPORT}

A 19-year-old female presented to the Endocrinology department with secondary amenorrhea. On detailed history, she had features of precocious puberty in the form of premature menarche at the age of three years, followed by thelarche and pubarche at six years. She was on medroxyprogesterone acetate for precocious puberty till the age of eleven years. After one year of stopping the drug, she started experiencing scanty vaginal bleeding once in 5-6 months, with secondary amenorrhea for past one year. She was tall compared to her twin sister and peers (Figure 1a) till twelve years age. No history suggestive of thyrotoxicosis, acromegaly, Cushing's 
syndrome, bony deformities, fractures, hearing loss or visual loss. She is the second of twins born out of nonconsanguineous marriage, postnatal period was uneventful. No family history of similar illness.

On examination, height was $154 \mathrm{~cm}\left(10^{\text {th }}\right.$ centile $)$, weight $70 \mathrm{~kg}$ with body mass index (BMI) of 29. Multiple café au lait spots with irregular borders (Figure 1b) the largest measuring $13 \times 7 \mathrm{~cm}$, acanthosis nigricans and abdominal striae were present. Secondary sexual characters and external genitalia were normal. No goiter, facial asymmetry, bony deformities or swellings. Other systemic examination was normal.

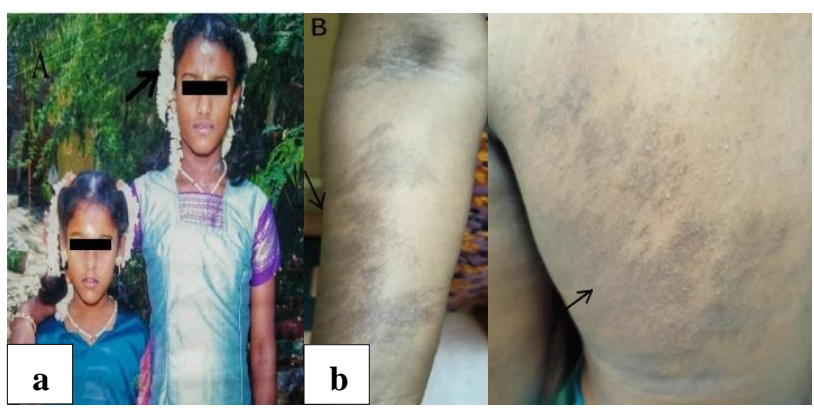

Figure 1: (a) Patient (marked with arrow) with twin sister at the age of 8 years, and (b) café au lait macules.

Complete hemogram, liver and renal function tests, blood glucose levels and urine routine were normal. Blood biochemistry revealed normal serum calcium of $8.8 \mathrm{mg} / \mathrm{dl}$ (N. 8.7-10.4 mg/dl), phosphorus of $3.11 \mathrm{mg} / \mathrm{dl}(\mathrm{N} .2 .45-$ $5.10 \mathrm{mg} / \mathrm{dl})$ and alkaline phosphatase of $122 \mathrm{U} / \mathrm{l}(\mathrm{N} .40-$ $136 \mathrm{U} / \mathrm{l})$. Hormonal profile showed pubertal range of luteinizing hormone $(\mathrm{LH})(\mathrm{N} .1 .2-12.5 \mathrm{mIU} / \mathrm{ml})$ and follicle-stimulating hormone $(\mathrm{FSH})(\mathrm{N} .2-15 \mathrm{mIU} / \mathrm{ml})$ with elevated estradiol level of $334 \mathrm{pg} / \mathrm{ml}$ (N 12.4-233 $\mathrm{pg} / \mathrm{ml})$. Prolactin, thyroid-stimulating hormone (TSH), free thyroxine (T4) and intact parathyroid hormone were normal. Overnight dexamethasone suppression test resulted in appropriate suppression of serum cortisol level to $0.811 \mu \mathrm{g} / \mathrm{dl}(\mathrm{N} .<1.8 \mu \mathrm{g} / \mathrm{dl}) .75 \mathrm{~g}$ glucose induced growth hormone level was $0.113 \mathrm{ng} / \mathrm{ml}(\mathrm{N} .<0.4 \mathrm{ng} / \mathrm{ml})$.

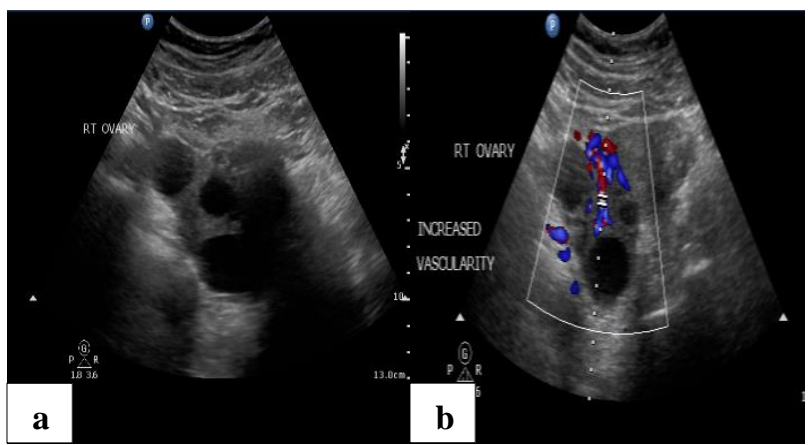

Figure 2: (a) Enlarged right ovary $(8.5 \times 4.8 \mathrm{~cm})$ with multiple follicles, (b) right ovary showing features of hyperstimulation and increased vascularity.

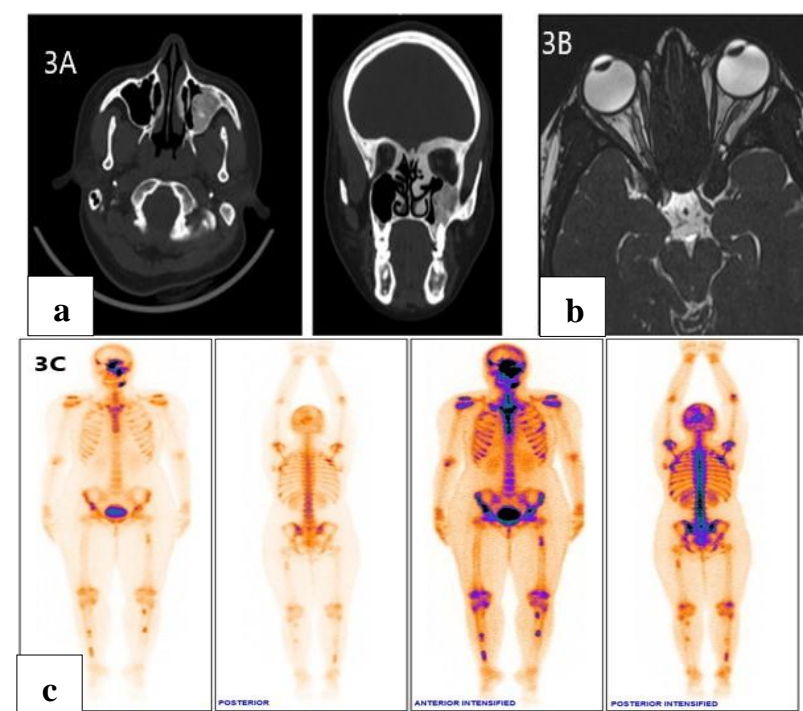

Figure 3: (a) CT brain coronal section - bilateral frontal, sphenoid, ethmoid bones, left maxilla and mandible expanded, sclerotic and show ground glass matrix suggestive of fibrous dysplasia; (b) MRI T2 Ciss sequence showing dysplastic bone encroaching bilateral optic foramina; and (c) Tc99 MDP bone scan showing polyostotic fibrous dysplasia.

Ultrasound abdomen and pelvis revealed enlarged right ovary $(8.5 \times 4.8 \mathrm{~cm})$ with increased vascularity and multiple follicles, largest measuring $3.6 \times 3.3 \mathrm{~cm}$ (Figure $2 \mathrm{a}$ and b). Computed tomography (CT) and magnetic resonance imaging (MRI) brain showed features suggestive polyostotic fibrous dysplasia involving bilateral frontal, sphenoid, ethmoid bones, left maxilla, and mandible, with encroachment of bilateral optic foramina (left>right)and left supraorbital fissure (Figure $3 \mathrm{a}$ and b). Tc-99 methylene diphosphate (MDP) bone scan confirmed polyostotic fibrous dysplasia, with increased uptake in sphenoid bone, mandible, frontal bonesupraorbital region, left $5^{\text {th }}, 9^{\text {th }}$ ribs, right scapula, proximal shaft of left femur and both tibiae (Figure $3 \mathrm{c}$ ).

Based on the clinical features and investigations, patient diagnosed to have MAS. She was given zoledronic acid infusion for fibrous dysplasia. Amenorrhea was treated with medroxyprogesterone $10 \mathrm{mg}$ daily for 14 days, followed by low dose combined oral contraceptive therapy, following which menstrual cycles resumed.

\section{DISCUSSION}

MAS is a rare disorder, caused by somatic activating mutations of guanine nucleotide binding protein 1 (GNAS1) leading to constitutive Gs $\alpha$ activation in a mosaic pattern. ${ }^{3,4}$ The most common endocrine manifestation of MAS is precocious puberty which is more common in girls than in boys. The first complaint in our patient was also precocious puberty. As in our case, ovarian hyperfunction typically manifests as gonadotropin independent precocious puberty (GIPP) to start with but 
may be complicated by central precocious puberty usually at a bone age of nine years or more ${ }^{5}$. Nonsequential precocious puberty is characteristically seen in GIPP, and the first manifestation may be premature menarche as in our case. Ovarian Gs $\alpha$ activation results in recurrent estrogen-producing cysts in about $85 \%$ of the girls and is responsible for causing premature menarche and other features of precocious puberty. ${ }^{3,5}$ In adult life, the cysts can cause menstrual irregularities, as is seen in our patient, by disrupting ovarian cycles. ${ }^{5}$ An increased prevalence of menstrual irregularities and hyperandrogenism have been reported in cases of precocious puberty in adolescence and adult life, probably due to a primary alteration in the GnRH pulse generator leading to an excessive LH pulsation persisting into adulthood or due to altered ovarian development due to premature exposure of the ovaries to gonadotrophins or other hormones associated with puberty. ${ }^{6}$ However, pregnancy is achievable and safe, though challenging. ${ }^{5}$ Hence, MAS should be kept in mind in girls with childhood onset premature menarche, followed by menstrual abnormalities in adolescence or adult life.

The other endocrine manifestations include thyroid lesions with or without nonimmune hyperthyroidism (50\%-60\%), pituitary (10-15\%) involvement leading to growth hormone excess and hyperprolactinemia. ${ }^{3-5}$ In our case, the sole endocrine manifestation was ovarian hyperfunction, but patient needs to be monitored for early diagnosis and management of other endocrine manifestations, especially pituitary adenoma leading to growth hormone excess in view of presence of extensive craniofacial fibrous dysplasia.

Fibrous dysplasia occurs in 46-98\% of patients with MAS, mostly polyostotic. ${ }^{3}$ It most commonly involves the skull and femur, as is present in our case. It may be asymptomatic as in our case or present with facial asymmetry, bony pain or deformities, pathological fractures or less often with more serious complications such as visual loss due to involvement of optic foramina or optic nerve, hearing loss due to temporal bone involvement, Arnold Chiari malformation and basilar invagination. ${ }^{4,5,7}$ Fibrous dysplasia lesions appear mainly in childhood and adolescence, with approximately $90 \%$ of future lesions being detectable on bone scans by 5 years of age. ${ }^{3,4}$ The appearance of new lesions or expansion of existing lesions in adulthood as seen in our case is rare. CT best delineates the bony lesions of fibrous dysplasia while MRI is the best modality to identify complications like optic nerve involvement and basilar invagination. MRI brain is hence an important tool, that in addition to detecting pituitary adenomas, will identify craniofacial fibrous dysplasia and associated complications as in our case and is particularly useful when bone scan is not readily available.

Firstline recommended treatment in MAS is letrozole, with tamoxifen and fulvestrant as second line or adjuvant therapy. ${ }^{4}$ However, medroxyprogesterone acetate, administered orally or as monthly intramuscular (IM) injections, is an easily available, economic options useful in resource limited settings. ${ }^{8}$ Medroxyprogesterone acetate is useful in both central and peripheral precocious puberty, by inhibiting central gonadotropin release by acting on hypothalamic pulse generator as well as by directly inhibiting gonadal steroidogenesis by inhibiting 3-beta hydroxysteroid dehydrogenase 2 enzyme. ${ }^{8}$

Our patient has all the three classical features required for diagnosis of MAS, namely precocious puberty, café au lait spots and fibrous dysplasia. As any two of these are enough to make a diagnosis, an earlier diagnosis of the condition was possible when she developed precocious puberty at the age of three years because café au lait macules were present since birth, though ignored by the parents and physicians at the time of diagnosis of precocious puberty. $^{3}$ Hence, a thorough clinical examination is of paramount importance in all cases of precocious puberty, irrespective of suspected etiology. All features need not be detected at the same time and may evolve with time as in our case, so vigilant follow up is required in all cases of precocious puberty.

\section{CONCLUSION}

A thorough clinical examination for café au lait macules and other features of MAS and other syndromes associated with precocious puberty is indispensable in all patients with precocious puberty. Close follow up and monitoring for coexisting endocrine and nonendocrine manifestations and associated complications are important for early diagnosis and optimal management. Possibility of MAS should be kept in mind when patients with precocious puberty in childhood present with menstrual abnormalities in later life. Rarely, fibrous dysplasia may remain asymptomatic despite extensive polyostotic lesions and active lesions may be present even at the age of 19 years.

\section{Funding: No funding sources \\ Conflict of interest: None declared \\ Ethical approval: Not required}

\section{REFERENCES}

1. de Castro LF, Ovejero D, Boyce AM. Diagnosis of endocrine disease: Mosaic disorders of FGF23 excess: Fibrous dysplasia/McCune-Albright syndrome and cutaneous skeletal hypophosphatemia syndrome. Eur J Endocrinol. 2020;182(5):83-99.

2. Corica D, Aversa T, Pepe G, De Luca F, Wasniewska M. Peculiarities of precocious puberty in boys and girls with McCune-Albright syndrome. Front Endocrinol (Lausanne). 2018;9:337.

3. Boyce AM, Collins MT. Fibrous dysplasia/McCuneAlbright syndrome: a rare, mosaic disease of $\mathrm{G} \alpha \mathrm{s}$ activation. Endocr Rev. 2020;41(2):345-70.

4. Javaid MK, Boyce A, Appelman-Dijkstra N, Ong J, Defabianis P, Offiah A, et al. Best practice management guidelines for fibrous 
dysplasia/McCune-Albright syndrome: a consensus statement from the FD/MAS international consortium. Orphanet J Rare Dis. 2019;14(1):1-17.

5. Spencer T, Pan KS, Collins MT, Boyce AM. The clinical spectrum of McCune-Albright syndrome and its management. Horm Res Paediatr. 2019;92(6):34756.

6. Lazar L, Meyerovitch J, de Vries L, Phillip M, Lebenthal Y. Treated and untreated women with idiopathic precocious puberty: long-term follow-up and reproductive outcome between the third and fifth decades. Clin Endocrinol (Oxf). 2014;80(4):570-6.

7. Subbiah S, Palikhe G, Bhadada SK, Mukherjee KK, Bhansali A. Acrogigantism and facial asymmetry:
McCune-Albright syndrome. J Pediatr Endocrinol Metab. 2011;24(9-10):835-7.

8. Kumar M, Mukhopadhyay S, Dutta D. Challenges and controversies in diagnosis and management of gonadotropin dependent precocious puberty: an Indian perspective. Indian $\mathrm{J}$ Endocrinol Metab. 2015;19(2):228.

Cite this article as: Subbiah S, Nazirudeen R, Natarajan S, Natarajan V, Jayaraman S. Secondary amenorrhea in a case of gonadotropin independent precocious puberty: McCune-Albright syndrome. Int J Reprod Contracept Obstet Gynecol 2021;10:3636-9. 